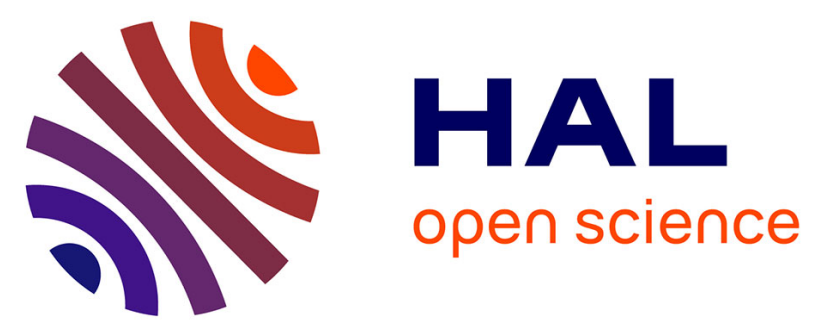

\title{
Tailored microstructure and mechanical properties of nanocomposite films made from polyacrylic/LDH hybrid latexes synthesized by RAFT-mediated emulsion polymerization
}

Florent Dalmas, Samuel Pearson, Baptiste Gary, J.-M. Chenal, Elodie Bourgeat-Lami, Vanessa Prévot, Laurent Chazeau

\section{To cite this version:}

Florent Dalmas, Samuel Pearson, Baptiste Gary, J.-M. Chenal, Elodie Bourgeat-Lami, et al.. Tailored microstructure and mechanical properties of nanocomposite films made from polyacrylic/LDH hybrid latexes synthesized by RAFT-mediated emulsion polymerization. Polymer Chemistry, 2018, 9 (19), pp.2590 - 2600. 10.1039/C8PY00268A . hal-01826571

\section{HAL Id: hal-01826571 \\ https://hal.science/hal-01826571}

Submitted on 8 Oct 2021

HAL is a multi-disciplinary open access archive for the deposit and dissemination of scientific research documents, whether they are published or not. The documents may come from teaching and research institutions in France or abroad, or from public or private research centers.
L'archive ouverte pluridisciplinaire HAL, est destinée au dépôt et à la diffusion de documents scientifiques de niveau recherche, publiés ou non, émanant des établissements d'enseignement et de recherche français ou étrangers, des laboratoires publics ou privés. 


\title{
Polymer Chemistry
}

\section{ARTICLE}

\section{Tailored microstructure and mechanical properties of nanocomposite films made from polyacrylic/LDH hybrid latexes synthesized by RAFT-mediated emulsion polymerization}

Received 00th January 20xx Accepted 00th January 20xx

DOI: $10.1039 / \times 0 \times x 00000 x$

www.rsc.org/

\author{
Florent Dalmas, ${ }^{\text {a }}$ Samuel Pearson, ${ }^{* b}$ Baptiste Gary, ${ }^{a}$ Jean-Marc Chenal, ${ }^{\text {a }}$ Elodie Bourgeat-Lami, ${ }^{b}$ \\ Vanessa Prévot ${ }^{\mathrm{c}}$ and Laurent Chazeau ${ }^{\mathrm{a}}$
}

\begin{abstract}
Layered Double Hydroxide (LDH)-filled nanocomposites were processed from film-forming latexes synthesized by macroRAFT-assisted encapsulating emulsion polymerization (REEP). Microstructure and thermomechanical behavior of the polymer matrices and corresponding nanocomposites were investigated by TEM, FIB-SEM, SAXS and DMA. Strong ionic interactions created between acrylic acid groups induce a lamellar nanostructuration of the P(AA-BA)-b-P(MA-BA) diblock copolymer matrix and are responsible for a high Young's modulus in the rubbery state that increases with the length (i.e., the molar mass) of the P(AA-BA) blocks. When filled with $16 \mathrm{wt} \%$ of $\mathrm{LDH}$, the intrinsic structure of the matrix is lost and the mechanical behavior of the nanocomposites is solely driven by the LDH dispersion and ionic interactions. Two types of percolation (i.e., mesh size of the LDH network and mechanical reinforcement) have been achieved by playing with the degree of segregation of the LDH nanoplatelets within the material.
\end{abstract}

\section{Introduction}

Polymeric nanocomposites encompass a large variety of materials composed of inorganic nanoparticles (also called nanofillers) dispersed in a polymer matrix. They are encountered in a wide range of industrial applications (e.g, from car tires to food packaging) to impart superior thermal, mechanical, electrical conduction, or permeation properties. Despite the large volume of literature in the field, nanocomposites are still the subject of many academic research papers. Indeed, while there is a general consensus on the determining role of polymer/filler interfaces in polymer nanocomposites, their synergistic effect is not fully understood. Optimizing the performance of nanocomposite materials thus requires a compromise between the intrinsic characteristics of the nanofillers (i.e., their chemical composition, size, shape and surface, electrical or mechanical properties), the interfacial properties (nature of the filler-filler ${ }^{1}$ and filler-matrix ${ }^{2,3}$ interactions), and the spatial organization of

\footnotetext{
a. Université de Lyon, INSA-Lyon, CNRS MATEIS UMR5510, 7 av J. Capelle, F-69621 Villeurbanne, France, *E-mail: florent.dalmas@insa-lyon.fr

b. Univ Lyon, Université Claude Bernard Lyon 1, CPE Lyon, CNRS, UMR 5265, Chemistry, Catalysis, Polymers and Processes (C2P2), 43 Bvd. du 11 Novembre 1918, F-69616 Villeurbanne, France, *E-mail: samueljohnpearson@outlook.com Université Clermont Auvergne, CNRS, ICCF - Institut de Chimie de ClermontFerrand, F-63000 Clermont-Ferrand, France
}

Electronic Supplementary Information (ESI) available: experimental details on synthesis of LDH and hybrid latexes precursors with TEM pictures and PXRD pattern of the raw LDH particles, cryo-TEM pictures of the synthesized latexes, TGA curves and PXRD patterns of the different LDH nanocomposite films studied. See DOI: $10.1039 / \mathrm{x} 0 \times x \times 0000 \mathrm{x}$ nanofiller within the composite material (i.e., the dispersion state and the microstructure). These features are indeed very interdependent. ${ }^{4-6}$ For instance, the formation of a percolating structure within the material is necessary to increase thermal or electrical conductivity of nanocomposites but, when stiff interparticle contacts are involved (through hydrogen bonding or electrostatic interactions for instance), it usually leads to an increase of the Young's modulus of the material at the expense of its elongation at break. ${ }^{1,7-12}$ On the other hand, improving gas permeation properties while maintaining optical transparency and softness of the material requires that the particles are uniformly dispersed and non-aggregated. ${ }^{13,14}$

Regardless of the type of nanoparticles (silica nanospheres, clay platelets, carbon nanotubes, cellulose whiskers, graphene sheets, etc.), several strategies have been explored in the literature to control the dispersion of nanofillers into polymeric nanocomposites. These can be divided into two basic categories. The first category involves processing techniques for combining pre-formed nanoparticles and polymer, such as melt blending and solvent casting, ${ }^{15,16}$ which often require chemical modification of the nanoparticle surface (polymer grafting ${ }^{17,18}$, functionalization ${ }^{19,20}$ ) prior to processing. The second category involves synthetic approaches for generating the polymer matrix or the nanofiller in the presence of the other component; these include in-situ polymerization, ${ }^{16}$ sol-gel chemistry, ${ }^{21}$ or ionic selforganization. $^{22,23}$

Among the various synthetic approaches, heterophase polymerization processes (e.g., emulsion, miniemulsion or dispersion polymerizations) have recently attracted significant 
attention as they offer unique opportunities to create nanostructured aqueous colloids (i.e., latexes) that can be easily processed into films with improved physical properties. ${ }^{24-27} \mathrm{~A}$ wide range of inorganic particles have been incorporated into polymer latexes leading to a variety of particle morphologies including encapsulated solids, janus, dumbbell-shaped, multipod-like and armored colloids, just to name a few. When processed into films, these composite particles have proven to significantly improve the final material properties such as electrical conductivity ${ }^{7,12,28}$ or mechanical resistance. ${ }^{29-31}$ In that respect, anisotropic fillers such as nanotubes or nanosheets present many advantages compared to isotropic fillers. Exfoliated clay platelets have been previously used as fillers for polymer latex films obtained through emulsion ${ }^{32-36}$ or miniemulsion ${ }^{37}$ polymerization. The final properties were shown to strongly depend on the film microstructure which, in turn, results from the particle morphology. For instance, Wang et al. showed that the addition of a small amount of Laponite-armored latex particles with a soft $\operatorname{poly}(n$-lauryl acrylate) core in a poly( $n$-butyl acrylate-co-acrylic acid) matrix significantly enhanced the mechanical properties of a pressure-sensitive adhesive film. ${ }^{37}$ In recent work, drying a suspension of clay-armored latexes allowed the formation of a three dimensional percolating network of Laponite discs spread throughout the latex film ${ }^{35,36}$ leading to composite materials with enhanced mechanical properties compared to films made from Laponite platelets encapsulated into polymer latex particles. ${ }^{3}$

In recent years, layered double hydroxides (LDHs), ${ }^{38}$ also known as anionic clays, have gained increasing attention as fillers ${ }^{39,40}$ in polymer nanocomposites, due not only to their $2 \mathrm{D}$ feature but also, more importantly, because of their tunable chemical composition. Their remarkably high anionic exchange capacity and highly hydroxylated layers compared to cationic clays make them interesting candidates for mechanical reinforcement and as corrosion inhibitors and flame retardants. Compared to smectite clays, examples of $\mathrm{LDH} /$ polymer nanocomposite suspensions are still sparse. This is most likely because the high intralayer charge density of the LDH platelets makes their exfoliation in water difficult, rendering the emulsion polymerization approach quite challenging. In addition, LDH aqueous suspensions usually display poor colloidal stability. ${ }^{41}$ Recently, we reported waterborne $\mathrm{LDH}$ nanocomposite films obtained using a colloidal approach by simple mixing and casting of surfactantfree poly(methacrylate-co- $n$-butyl acrylate) (P(MA-co-BA)) latexes and aqueous LDH suspensions. ${ }^{42}$ Above a certain LDH content, it was shown that the formation of a stiff $L D H$ percolating network was induced by heterocoagulation, resulting in a high mechanical reinforcement. Nevertheless, the formation of such a percolating network has several drawbacks, as it facilitates the creation of paths for water diffusion, and as its high stiffness is obtained at the expense of a very low reversible deformability.

Recently, a versatile method employing the reversible addition-fragmentation chain-transfer (RAFT) polymerization technique was developed for the surfactant-free synthesis of organic/inorganic composite particles in aqueous dispersed media. This strategy, coined macroRAFT-assisted encapsulating emulsion polymerization (REEP), ${ }^{43,44}$ uses living amphipathic random copolymers which interact with the surface of inorganic particles and favor their encapsulation through emulsion polymerization. Using the REEP strategy, we recently succeeded in synthesizing LDH-based nanocomposite (P(MAco-BA)) latex particles of various morphologies by tuning the nature and composition of the macroRAFT agent. ${ }^{45}$ The present work now aims at investigating the mechanical properties of the nanocomposite films obtained from these latexes and establishing the impact of film microstructure on their properties. The structure and the microstructure of the films were first characterized using powder X-ray diffraction (PXRD) and two-dimensional wide and small angle X-ray scattering (WAXS and SAXS). A multi-scale analysis of the LDH dispersion within the nanocomposites was also conducted by transmission electron microscopy (TEM) and coupled focused ion beam / scanning electron microscopy (FIB-SEM). Finally, the mechanical properties were studied using dynamic mechanical analysis (DMA).

\section{Materials and methods}

\section{Synthesis}

The $\mathrm{Mg}_{3} \mathrm{Al}-\mathrm{CO}_{3} \mathrm{LDH}$ particles were prepared by fast coprecipitation followed by hydrothermal treatment, ${ }^{42,46}$ (see SI Figure S1 for TEM and PXRD characterization of pristine LDH particles) and incorporated into film-forming latexes by REEP adapted from our previous work ${ }^{45}$ (for details see $\mathrm{SI}$ ). For this purpose, two statistical copolymers of acrylic acid (AA) and $n$ butyl acrylate (BA) were first synthesized by RAFT polymerization (more details are given in $\mathrm{SI}$ ), giving poly $\left(\mathrm{AA}_{7.5^{-}}\right.$ stat-BA $\left.A_{7.5}\right)$-RAFT and poly $\left(A_{1} A_{17.5}\right.$-stat-BA $\left.A_{17.5}\right)$-RAFT, hereafter referred to as $P(A A-B A)_{15}-R$ and $P(A A-B A)_{35}-R$, respectively. These negatively-charged macroRAFT (MR) agents were then electrostatically adsorbed onto the surface of the positivelycharged LDH particles, providing both colloidal stability, ${ }^{47}$ and a re-activatable group (the RAFT function) from which polymerization could be recommenced during the subsequent REEP. ${ }^{45} \mathrm{~A}$ third copolymer, poly $\left(\mathrm{AA}_{17.5}\right.$-stat- $\left.\mathrm{BA}_{17.5}\right)$ (hereafter referred to as $P(A A-B A)_{35}$ ) was obtained by replacing the reactivatable RAFT function of $P(A A-B A)_{35}-R$ with a nonreactivatable group. Once adsorbed onto $L D H$ surface, this last one constitutes a third type of starting stable LDH suspension without any RAFT function. From these three LDH suspensions, only differing in their absorbed macroRAFT agents, latex particles were formed by starve-feed emulsion polymerization of a methyl acrylate (MA)/BA monomer mixture $(80: 20 \mathrm{w} / \mathrm{w})$ using a water soluble initiator. As illustrated in Figure $S 2$, the nature of the adsorbed copolymer proved critical to the morphology of these resulting latexes. The two systems based on $\mathrm{P}(\mathrm{AA}-\mathrm{BA})_{15}-\mathrm{R}$ and $\mathrm{P}(\mathrm{AA}-\mathrm{BA})_{35}-\mathrm{R}$ gave an encapsulated and a dumbbell morphology respectively, with the RAFT function ensuring that the stabilizing macroRAFT species were chain extended with the fed monomer to give block copolymers. In 
contrast, the $\mathrm{P}(\mathrm{AA}-\mathrm{BA})_{35}$ system gave an armored morphology due to the inability to chain extend from the stabilizing polymer, resulting in uncontrolled growth of $P(M A-B A)$. These morphologies are recalled in Table 1 . In addition, for comparison, two LDH-free latexes were synthesized using $P(A A-B A)_{15}-R$ and $P(A A-B A)_{35}-R$ by simply omitting the $L D H$ from the respective REEP polymerizations. This results in the formation of block copolymers that assemble in-situ to form self-stabilized particles with a $\mathrm{P}(\mathrm{MA}-\mathrm{BA})$ core and a $\mathrm{P}(\mathrm{AA}-\mathrm{BA})$ shell according to the so-called polymerization-induced self- assembly (PISA) process. ${ }^{48}$ Finally, to evaluate the effect of the macroRAFT agents on film properties, a P(MA-BA) (80:20 w/w) latex, solely stabilized by initiator fragments, was synthesized by conventional surfactant-free emulsion polymerization. Table 1 sums up the main characteristics of the different latexes synthesized in this study. Films were formed from all 6 samples by casting solutions in a $5 \mathrm{~cm}$ diameter teflon mold, and allowing them to dry at $25^{\circ} \mathrm{C}$ in a ventilated oven for 5 days. All processed materials display a main relaxation temperature, $\mathrm{T} \alpha$, by DMA at $1 \mathrm{~Hz}$ of about $12^{\circ} \mathrm{C}$.

Table 1 - Name and composition of the different synthesized latexes. The observed morphologies for the three LDH nanocomposite latexes are given.

\begin{tabular}{|c|c|c|c|c|c|c|c|}
\hline \multirow{2}{*}{ Sample name } & \multirow{2}{*}{$\mathrm{LDH}(w t \%)^{\mathrm{a}}$} & \multicolumn{2}{|c|}{ MacroRAFT agent } & \multirow{2}{*}{$\begin{array}{c}P(M A-B A) \\
(80: 20 w / w) \\
(w t \%)^{b}\end{array}$} & \multirow{2}{*}{$\begin{array}{l}\text { Theoretical/expeimental }{ }^{\mathrm{c}} \text { molar } \\
\text { mass }\left(\mathrm{g} \cdot \mathrm{mol}^{-1} \text { ) [and } \boxminus\right] \text { of the final } \\
\text { polymer phase }\end{array}$} & \multirow{2}{*}{$\begin{array}{l}\text { Particle } \\
\text { diameter } \\
(\mathrm{nm})^{\mathrm{d}}\end{array}$} & \multirow{2}{*}{ Particle morphology ${ }^{\mathrm{e}}$} \\
\hline & & Type & wt $\%^{b}$ & & & & \\
\hline LDHMR15 & 16 & $\mathrm{P}(\mathrm{AA}-\mathrm{BA})_{15}-\mathrm{R}$ & 12.8 & 71.2 & $12200 / 12700[1.5]$ & $129 \pm 44$ & Encapsulated \\
\hline LDHMR35 & 17.5 & $\mathrm{P}(\mathrm{AA}-\mathrm{BA})_{35}-\mathrm{R}$ & 12.5 & 71.5 & $25300 / 21500$ [1.7] & $129 \pm 40$ & Dumbbell \\
\hline LDHM & 15 & $\mathrm{P}(\mathrm{AA}-\mathrm{BA})_{35}$ & 12.8 & 71.2 & $-/ 151000^{f}[3.8]$ & $144 \pm 51$ & Armored \\
\hline Blank MR15 & - & $\mathrm{P}(\mathrm{AA}-\mathrm{BA})_{15}-\mathrm{R}$ & 17 & 83 & $10900 / 10200[1.6]$ & $12 \pm 4$ & Self-assembled block \\
\hline Blank MR35 & - & $\mathrm{P}(\mathrm{AA}-\mathrm{BA})_{35}-\mathrm{R}$ & 17 & 83 & $22200 / 18200$ [2.3] & $16 \pm 7$ & copolymers \\
\hline $\mathrm{P}(\mathrm{MA}-\mathrm{BA})$ & - & - & - & 100 & $-/ 103000^{\mathrm{g}}[3.6]$ & $694 \pm 150$ & Latex spheres \\
\hline
\end{tabular}

\section{Characterizations}

For conventional TEM observations, thin sections were prepared by cryo-ultramicrotomy using a Leica Ultracut UCT microtome with a diamond knife. The temperature of the sample was set to $-40^{\circ} \mathrm{C}$ and the speed of the glass knife was $0.2 \mathrm{~mm} \mathrm{~s}^{-1}$. Thin sections of about $70 \mathrm{~nm}$ thick were drycollected and placed on a 400-mesh copper grid. TEM images were acquired using a CM120 Philips transmission electron microscope operating at an accelerating voltage of $120 \mathrm{kV}$. In order to minimize the degradation of the samples, all observations were carried out at $-170^{\circ} \mathrm{C}$. Precise scans of various regions of the sample were systematically done, starting at a small magnification which was then gradually increased. For blank materials, a small objective aperture was inserted in order to improve the mass-thickness contrast. For larger scale microstructural observations, sectioning and imaging of the nanocomposites was performed using a dual column focused ion beam (FIB)-scanning electron microscope (SEM) ZEISS NVision40. $\mathrm{A} \mathrm{Ga}^{2+}$ ion beam accelerated at $30 \mathrm{kV}$ was used. A 2 step milling procedure was employed on the bulk nanocomposites, which had been metalized with gold beforehand. First, a bulk trapezoid was milled at high current beam ( $4 n A)$ so that the shorter face could be imaged by the electron beam up to depth of at least $15 \mu \mathrm{m}$. Then, a final polishing of the observed surface was carried out with a fine current beam ( $80 \mathrm{pA})$. The SEM images of the polished surface were then recorded with an accelerating voltage of $5 \mathrm{kV}$, using an in-lens secondary electron (SE) detector. Such imaging conditions allow observation of insulating materials with minimal charging effects, high resolution, and a good contrast between the inorganic and organic phases. ${ }^{49}$

Powder X-ray diffraction patterns were recorded on a X'Pert Pro Philips diffractometer with a diffracted beam graphite monochromator and a $\mathrm{Cu} \mathrm{K} \alpha$ radiation source in the $2 \theta$ range of 5 to $70^{\circ}$ with a step of $0.013^{\circ}$ and a counting time per step of $20 \mathrm{~s}$.

Thermogravimetric analyses (TGA) were performed using a Setaram TGA92 thermogravimetric analyzer in the temperature range of $25-1100{ }^{\circ} \mathrm{C}$, with a heating rate of $5{ }^{\circ} \mathrm{C}$ $\mathrm{min}^{-1}$, under air atmosphere (thermograms are shown in Figure S1 of supplementary information).

Dynamic mechanical analysis (DMA) measurements were performed in torsion mode at a fixed frequency $(1 \mathrm{~Hz})$ from $200 \mathrm{~K}$ up to the flowing of the materials (when the DMA device fails at measuring), with a heating rate of $1 \mathrm{~K} \mathrm{~min}^{-1}$. The complex shear modulus, $\mathrm{G}^{*}$, was measured as a function of temperature. Samples were cut to dimensions of about $10 \times 3 \times 0.3 \mathrm{~mm}^{3}$ from casted films by avoiding edges of the films to ensure a constant film thickness. Since the acrylic acid function is highly hydrophilic, all the samples containing 
macroRAFT agents were previously dried at $350 \mathrm{~K}$ under vacuum once mounted in the clamps. To minimize modulus uncertainties due to sample dimensions uncertainties, all moduli of the blank materials were normalised, by a multiplicative factor, to the same modulus value as the pure latex matrix in the glassy state at $200 \mathrm{~K}$, since the same modulus is expected well below T $\alpha$ for all those unfilled polymers. On the other hand, in the glassy state, the same mechanical reinforcement is expected for all nanocomposites irrespective of the LDH dispersion, ${ }^{50}$ and is usually described as follows: $:^{51}$

$$
E_{3 D}=0.184 E_{/ /}+0.816 E_{\perp}
$$

where $E_{3 D}$ is the composite modulus, $E_{\|}$and $E_{\perp}$ are the parallel and perpendicular moduli calculated for a unidirectional platelet ply, given by the Halpin-Tsai formula. ${ }^{52}$ For the calculation, values of 100 and $15 \mathrm{GPa}$ were used for the longitudinal and transversal moduli of the LDH platelets, respectively, a Poisson's ratio of 0.4 , and a LDH aspect ratio of $15 .^{42}$

Wide angle $x$-ray scattering (WAXS) measurements were carried out on an X-ray apparatus equipped with a copper rotating anode ( $\lambda=1.54 \AA$ 施 (Rigaku Corporation, Japan), a Gobel's mirrors collimation system (Elexience, France) and a 2D detector (Princeton Instruments, USA). The patterns were acquired for $5 \mathrm{~min}$.

Small angle X-ray scattering experiments were carried out on the D2AM beam-line of the European Synchrotron Radiation Facility (ESRF), France. The energy was set at $9.5 \mathrm{keV}$. The twodimensional (2D) patterns were recorded by a photon counting pixel detector (XPAD 3). Each pattern was integrated azimuthally and corrected from the background scattering. The distance between sample and detector was set at $1600 \mathrm{~mm}$. The exposure time was set at 5 seconds.

\section{Results and discussion}

\section{Properties of the polymer matrices}

presents the evolution of the $G^{\prime}$ modulus with the temperature obtained by DMA on the blank materials (i.e., without LDH). First, one has to keep in mind that when a macroRAFT agent (MR) is used for the synthesis, a diblock copolymer is obtained from the $\mathrm{P}(\mathrm{AA}-\mathrm{BA})$ block of the MR and the polymerized $P(M A-B A)$ chains. Calculation gives ca. $17 \mathrm{wt} \%$ of $\mathrm{P}(\mathrm{AA}-\mathrm{BA})$ block in both blank materials. This amphiphilic block copolymer forms in water self-stabilized particles with a hydrophobic $P(M A-B A)$ core and a hydrophilic $P(A A-B A)$ shell. In comparison to the pure $P(M A-B A)$ latex film obtained by surfactant-free emulsion polymerization $\left(M_{\mathrm{n}, \mathrm{SEC}}=103000\right.$ g. $\mathrm{mol}^{-1}$ ), in which the modulus at the rubbery plateau is only due to the presence of entanglements, the presence of a $\mathrm{P}(\mathrm{AA}$ BA) block attached to $P(M A-B A)$ chains $\left(M_{n, S E C}=21500 \mathrm{~g} \mathrm{~mol}^{-1}\right.$ for the entire block copolymer Blank MR35, Table 1) leads to an important mechanical reinforcement: in the rubbery state, the modulus value of the Blank MR35 is around 10 times higher than the modulus of the $\mathrm{P}(\mathrm{MA}-\mathrm{BA})$ despite its lower molar mass that would normally be expected to exhibit flow at a temperature well below $350 \mathrm{~K}$. The absence of flow at temperature up to $400 \mathrm{~K}$ and the very long rubbery plateau indicates the presence of strong intermolecular ionic interactions, which can arise between the carboxylate groups of the MR and their counterions introduced for the deprotonation of the MR agent and its solubilization in water. The same effect has been previously reported for similar diblock ionomers (made of polymer and ionomer blocks with a total amount of ionic monomers lower than ca. 20 mol\%), which showed a large modulus in the rubbery plateau that slowly decreased with temperature. This slow decrease in modulus was ascribed to the thermo-reversibility of the strong inter-molecular ionic links. ${ }^{53}$ The same behavior is observed for Blank MR15, even if the modulus values measured in the rubbery domain are much smaller than those of Blank MR35.

As a comparison, Chenal et al. have previously highlighted the formation of a light PAA percolating network within a film formed from a $\mathrm{P}(\mathrm{AA}-b-\mathrm{BA})$ block copolymer synthesized by the PISA approach. ${ }^{54,55}$ In this study, higher molecular mass was obtained for the copolymer (typically $>80000 \mathrm{~g} \mathrm{~mol}^{-1}$ ) with an acrylic acid content of $3 \mathrm{wt} \%$, slightly lower than in the present work (between 5 and 6 wt\% for both blank systems). As a result, the authors highlighted the formation of core-shell latex beads of $80 \mathrm{~nm}$ diameter whereas much smaller particles are obtained in the suspension here (see Table 1). The authors also observed by DMA a long rubbery plateau with a Young's modulus level of about $0.5 \mathrm{MPa}$, in the same range as the one obtained for the MR15 sample in the present study. However, the ionic block consists, in our case, in a random AA/BA copolymer. Considering this, the ionic block content is about 20 wt\% in the present study; this can explain the higher Young's modulus observed in the rubbery plateau, especially for the MR35 film, even though the overall molar mass of the copolymers is lower than in ${ }^{54,55}$.

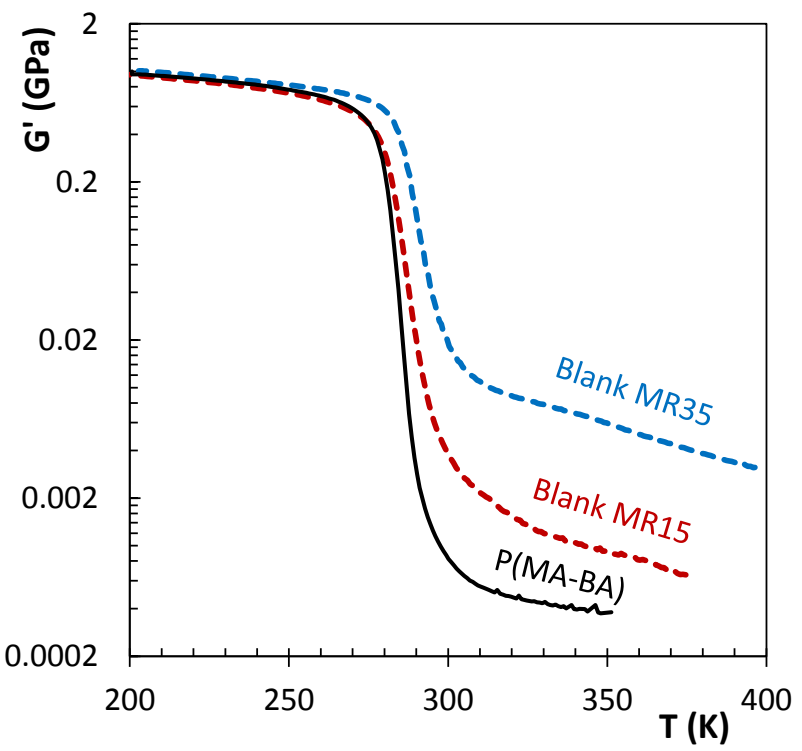

Figure 1 - Evolution of the storage modulus, $G^{\prime}$, as a function of temperature for the films prepared from the $P(M A-B A)$ latexes synthesized in the presence of $P(A A-B A)_{15}-R$ and $P(A A-B A)_{35}-R$ macroRAFT agents compared to the behavior of the film made from surfactant-free latex particles synthesized under the same conditions in the absence of macroRAFT. 
The microstructure of these blank materials was then investigated through SAXS experiments whose results are shown in Figure 2. The appearance of a correlation peak is obvious for both MR15- and MR35-based materials at $q^{*}$ values of $0.49 \mathrm{~nm}^{-1}$ and $0.25 \mathrm{~nm}^{-1}$, respectively. These correspond to characteristic distances of $13 \mathrm{~nm}$ and $25 \mathrm{~nm}$ for MR15 and MR35, respectively. A closer look at the SAXS pattern of the MR35-stabilized latex film also shows the first harmonic peak around $\mathrm{q}_{2}=0.5 \mathrm{~nm}^{-1}$, with the $\mathrm{q}_{2} / \mathrm{q}^{*}$ ratio of 2 confirming a lamellar arrangement. No structuration is observed for the pure P(MA-BA) latex film.

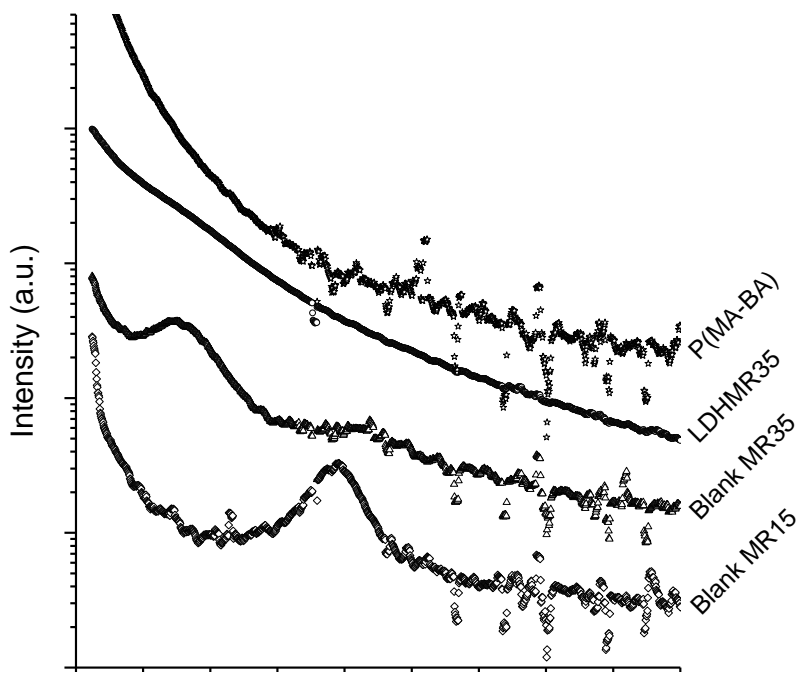

Figure 2 - SAXS patterns obtained for all unfilled films and for the LDHMR35 nanocomposite.
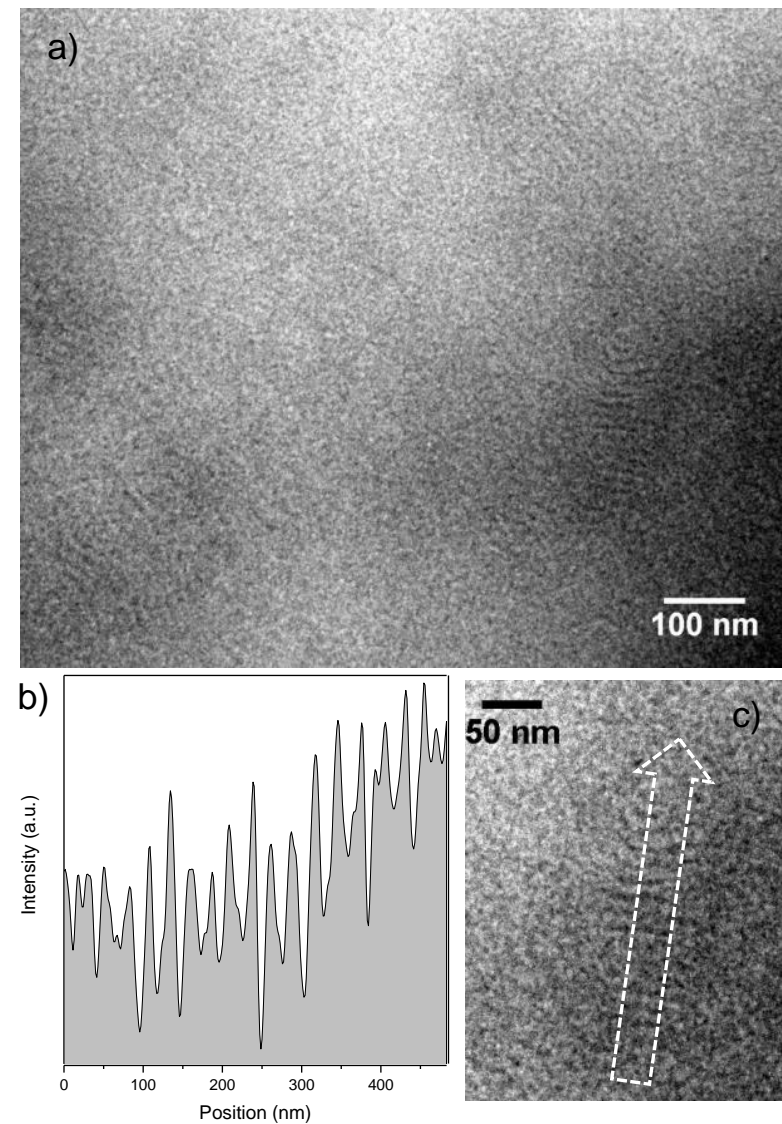

Figure 3 - a) TEM image and b) integrated intensity profile along the indicated arrow in c) crossing a structured domain for the Blank MR35 material.
Figure 3a presents a TEM observation of the blank MR35 sample. Some organized lamellar domains are clearly observed when oriented parallel to the electron beam. The weak contrast in the image is related to the density contrast between densely packed MR ionic blocks (appearing darker) and the amorphous $\mathrm{P}(\mathrm{MA}-\mathrm{BA})$ blocks. An intensity profile integrated on the TEM image along one of these domains (Figure $3 \mathrm{~b}$ and $3 c$ ) shows an average periodicity of $(27 \pm 3) \mathrm{nm}$ for this lamellar structure, which is in excellent agreement with the SAXS results. Nevertheless, a lamellar morphology would not usually be expected for diblock copolymers with this range of weight ratio (17/83 wt\%). ${ }^{56}$ An ionic phase is however known to perturb the thermal equilibrium of a block copolymer microstructure. For instance, Mani et al. demonstrated that in sulfonated polystyrene- $b$-poly(ethylenepropylene) block copolymers (SPS-PEP), physical cross-linking through ionic groups in the SPS block increased the thermodynamic repulsion between the dissimilar blocks. ${ }^{53}$ This induced a change in the copolymer microstructure from a hexagonal packing of cylinders for a non-ionic block copolymer made of $20 w t \%$ of PS and 80 wt\% of PEP, to lamellae for the corresponding ionomer after partial sulfonation and ionic neutralization of the PS block.

To sum up, both types of unfilled latexes synthesized in presence of macroRAFT agents show an intrinsic nanostructuration consisting in a lamellar arrangement of alternatively packed ionic MR blocks and amorphous P(MA-BA) chains, as illustrated in Figure 4.

Assuming equal densities for both blocks, the lamellae thickness for the MR block ( $d_{M R}$ ) and for the P(MA-BA) block $\left(d_{p}\right)$ can be calculated from their weight fractions and the long period $\left(d_{1}\right)$ extracted from SAXS experiments (Table 2 ). As expected and as usually found for similar diblock ionomers, 53,57 the shorter the MR block, i.e., the lower the molar mass of the hydrophobic $\mathrm{P}(\mathrm{MA}-\mathrm{BA})$ block, the thinner the lamellae.

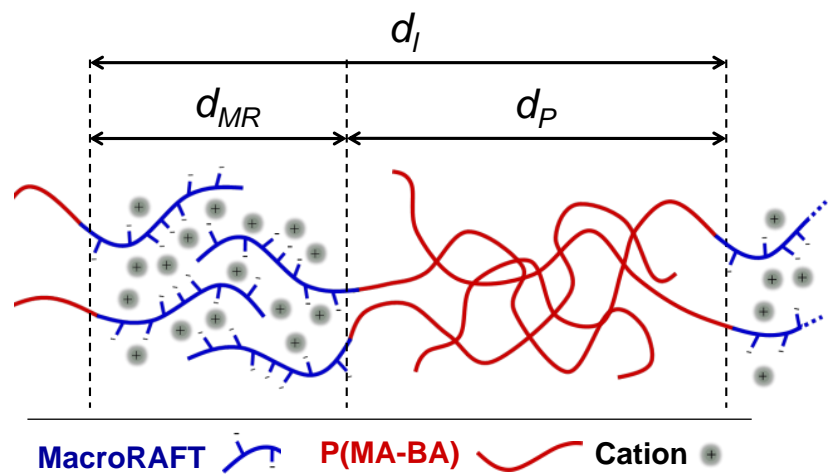

Figure 4 - Schematic representation of the morphology proposed for films generated from $P(M A-B A)$ latexes synthesized in the presence of macroRAFT agents. 
Table 2 - Microstructure parameters and molar masses for both blank materials.

\begin{tabular}{cccccc}
\hline & \multicolumn{4}{c}{ MR block } & \multicolumn{2}{c}{ P(MA-BA) block } \\
\hline & $\mathrm{d}_{l}(\mathrm{~nm})^{\mathrm{a}}$ & $\begin{array}{c}\mathrm{M}_{\mathrm{n}} \\
\left(\mathrm{g} \mathrm{mol}^{-1}\right)^{\mathrm{b}}\end{array}$ & $\begin{array}{c}\mathrm{d}_{\mathrm{MR}} \\
(\mathrm{nm})^{\mathrm{c}}\end{array}$ & $\begin{array}{c}\mathrm{M}_{\mathrm{n}} \\
\left(\mathrm{g} \mathrm{mol}^{-1}\right)^{\mathrm{b}}\end{array}$ & $\begin{array}{c}\mathrm{d}_{\mathrm{p}} \\
(\mathrm{nm})^{\mathrm{c}}\end{array}$ \\
\cline { 2 - 6 } Blank MR15 & 13 & 1858 & 2.2 & 8342 & 10.8 \\
Blank MR35 & 25 & 3767 & 4.2 & 14433 & 20.8 \\
\hline${ }^{a}$ Determined by SAXS. ${ }^{\mathrm{b}}$ Determined by SEC. ${ }^{\mathrm{c}}$ Calculated from $\mathrm{d}_{\mathrm{l}}$. &
\end{tabular}

Given the very large fraction of MA in the P(MA-BA) block ( 80 wt\%), one can reasonably approximate the Kuhn segment length of this block in the melt state by that of a PMA chain of the same molar mass. The review of Fetters et al. reports that $\left\langle R^{2}\right\rangle_{0} / M$ is equal to $0.436 \AA^{2}$ mol.g $g^{-1}$ for PMA in the melt state. $^{58}$ One can therefore estimate the gyration radii that the P(MA-BA) blocks of Blank MR15 and Blank MR35 would exhibit in the melt state without the presence of the MR block, giving $4 \mathrm{~nm}$ and $7 \mathrm{~nm}$ respectively. These values are more than twice lower than $d_{p}$, suggesting that the polymer chains in the PMABA blocks are likely slightly extended in the direction perpendicular to the lamellae and that they are likely to be less entangled than the same chains without MR blocks. The materials' microstructure can therefore be represented as in Figure 4 , which is consistent with the viscoelastic behaviours previously discussed: in a very similar way to ionomers, ${ }^{57}$ these materials show an important mechanical reinforcement in the rubbery state, in a temperature range where, given their molar masses, the P(MA-BA) chains should be fully viscous. The lower modulus value in the rubbery domain found for Blank MR15 may be explained by a smaller number of entanglements between chains than in Blank MR35, and by the lower number of intermolecular ionic interaction in the MR block. ${ }^{59,60}$

\section{Microstructure and thermo-mechanical behavior of the LDH-filled nanocomposites}

XRD measurements of the three nanocomposite films (Figure 5) show characteristic reflection peaks of pure $\mathrm{LDH}$ superimposed on the amorphous signal of the polymer matrix (Figure 5 and SI Figure S4), verifying the presence of LDH nanoparticles in the matrices. In particular, the (003) diffraction peak remains at the same angle value as that of pure $\operatorname{LDH}\left(11^{\circ}\right)$, corresponding to an unchanged LDH interlayer spacing of $0.76 \mathrm{~nm}$ (see SI Figure S1 for raw LDH PXRD pattern). This means that no swelling or exfoliation of the individual sheets making up each LDH particle occurred by growth of the polymer chains during the latex synthesis, which was expected given the high stability of carbonate as intercalating anion. As illustrated in Figure 6 for LDHMR35, all nanocomposites showed an isotropic diffraction ring for the (003) basal planes irrespective of whether the X-ray beam was perpendicular or parallel to the film thickness (Figure $6 \mathrm{~b}$ and $6 c$, respectively). This highlights the isotropic dispersion in volume of the platelets within the films.

To visualize the consequence of the starting latex morphology on the nanocomposite film microstructures, SEM experiments were carried out for the films obtained from the

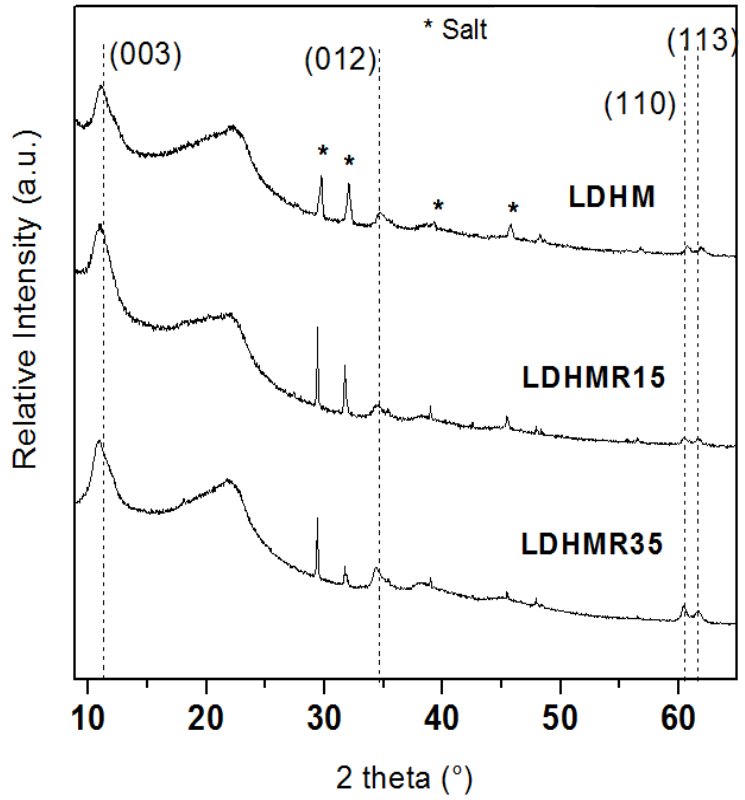

Figure 5 - PXRD patterns of LDH-filled nanocomposites.

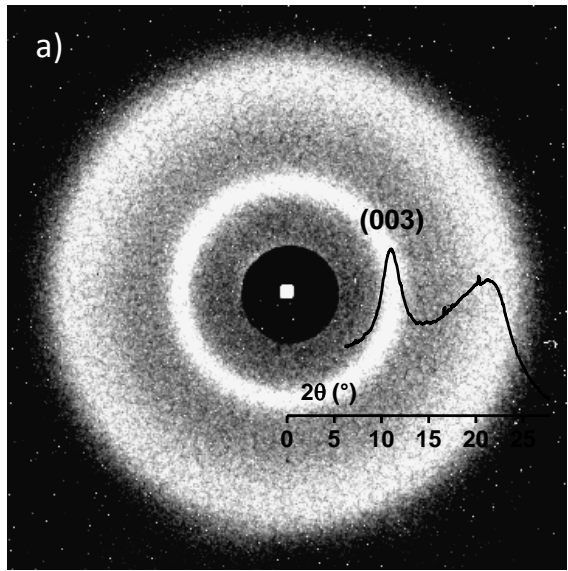

b)

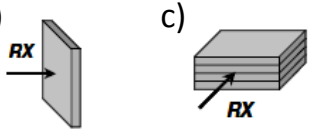

Figure 6 - a) Example of a 2D WAXS pattern for the LDHMR35 nanocomposite film oriented perpendicular with respect to the $X$-ray beam as illustrated in b). Similar pattern was obtained for a parallel orientation of the film (c) indicating isotropic distribution of the platelets within the film.

"encapsulated" and "dumbbell" morphology latexes, i.e., LDHMR15 and LDHMR35, respectively. A homogeneous dispersion of the platelets within the polymer is highlighted at large scale by SEM observation of a FIB milled cross section in Figure 7 with no obvious difference between the two systems. Bearing in mind that the contrast between the platelets and the polymer matrix depends on their relative orientation with respect to the electron beam, ${ }^{61}$ observations by TEM at larger magnification (Figure 7, bottom) confirm the good dispersion of LDH platelets. TEM observation of the LDH particles (which are therefore parallel to the electron beam, i.e., darker in the bright field images and appear as objects of 5-8 $\mathrm{nm}$ thickness) indicates that the primary reinforcing fillers are mainly stacks 
of about $10 \mathrm{LDH}$ sheets. In the film obtained from the LDHarmored particles (LDHM), a percolation network of LDH is observed, with a mesh size in the range of the latex bead diameter (about $130 \mathrm{~nm}$, see Figure 7). Such a network was expected as the clay platelets are located exclusively at the latex particle surface. The wavy shape observed for the the interface between latex particles during the film forming process. The deformed latex particles induce an approximate ring-like structure of the network mesh, slightly different from a typical honeycomb structure that could have been expected. This is very similar to what was previously observed for films prepared by heterocoagulation of $\mathrm{P}(\mathrm{MA}-\mathrm{BA})$ latex and $\mathrm{LDH} .{ }^{42}$

\section{LDHMR15}
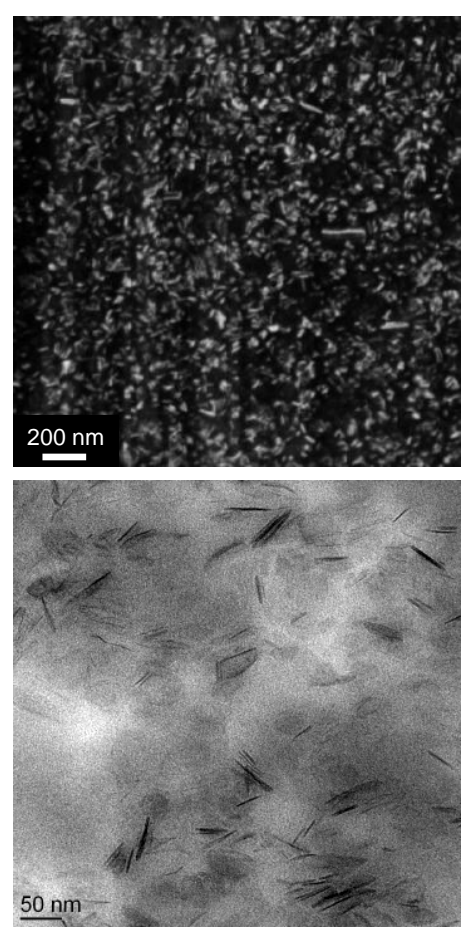

Figure 7 - FIB-SEM observations (top) and high magnification TEM micrographs (bottom) of LDH-filled nanocomposites: LDHMR15, LDHMR35 and LDHM from left to right, respectively

network walls may result from mechanical forces involved at

The SAXS pattern obtained for the LDHMR35 nanocomposite is shown in Figure 2. No correlation peak is observed for this material in the investigated $q$ range (i.e. for characteristic distances lower than $51 \mathrm{~nm}$ ), whereas a lamellar structure was previously highlighted for the blank MR35. This confirms the good dispersion of the LDH platelets, and also reveals that the lamellar organization of the organic phase is hindered by the LDH. Indeed, one can assume that the LDH platelets come in addition or in substitution of the cations associated to the carboxylate groups. For instance, Thakur et al. ${ }^{62}$ proposed that LDH particles counterbalance the ionic crosslinking in LDHfilled carboxylated nitrile rubber prepared by physical mixing in presence of $\mathrm{ZnO}$. In the present case, this should strongly modify the ionic aggregation of the MR block. Moreover, when synthesized by REEP with LDH, as recalled in Table 1, the obtained latexes are particles with a diameter around $100 \mathrm{~nm}$, this is very different from the blank materials which were obtained as much smaller micellar suspensions. Initially, the major part of the macroRAFT agent is electrostatically anchored on the LDH surface, which prevents the nanostructuration of the copolymer in the latex particle during the PMA-BA polymerization. Nevertheless, this polymerization

This journal is (C) The Royal Society of Chemistry 20xx

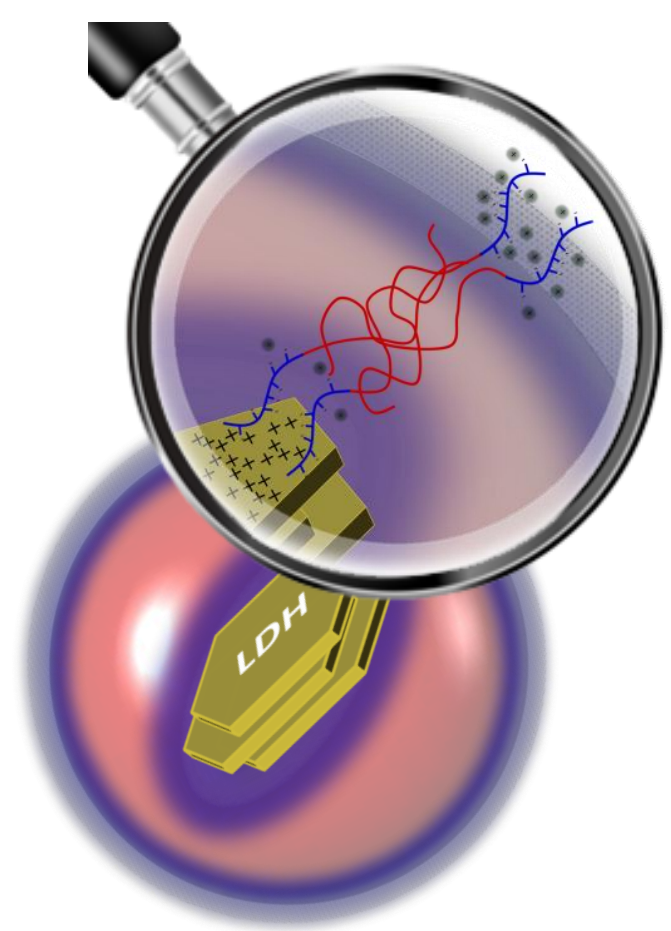

Figure 8 - Schematic representation of a latex particle synthesized in the presence of macroRAFT agent, showing the encapsulation of LDH platelets and detailing the proposed LDH-polymer and polymer-water interfaces (see Figure 4 for legend). 
most likely leads to the formation of a macroRAFT-rich layer around the latex particles to assure their colloidal stability, as depicted in Figure 8. The recruitment of free $M R$, i.e., $M R$ which is not initially anchored to the platelets, from solution to the growing polymer shell has been implicated in other REEP systems as a mechanism to maintain colloidal stability, since the macroRAFT agent is always initially in excess.

presents the mechanical properties of the LDH-filled nanocomposites and of the corresponding blank matrices. The former have much higher plateau moduli above $T_{\alpha}$. For the film obtained from the LDH-armored particles (LDHM), the strong mechanical reinforcement shown in, with an almost constant modulus in the rubbery plateau, is typical of the behavior of a composite in which the fillers have mechanically percolated. $^{3,35,36,42}$ This reinforcement should be the consequence of the build up of a LDH network during film formation, promoted by the original localization of the LDH platelets on the latex particle surface. The very high thermal stability of the modulus up to $420 \mathrm{~K}$ strongly suggests that the mechanical properties of this system are mainly driven by the relatively high stiffness of direct platelet-platelet contacts (even though indirect platelet-platelet links through some $\mathrm{P}(\mathrm{AA}-\mathrm{BA})_{35}$ chains shouldn't be excluded). Such direct contacts seem to be largely hindered in LDHMR15 and LDHMR35 since their moduli in the rubbery domain slowly drop with temperature. Both display very similar storage modulus curves, with moduli in the rubbery domain more than two-fold lower than that of LDHM. This lower reinforcement results partly from the localization of the LDH inside the latex particles, which makes the formation of a LDH network during the film formation more difficult. Nevertheless, its magnitude is too high to be ascribed solely to the classical reinforcement mechanism of dispersed platelets in a polymer matrix. Even though the lamellar microstructure of the copolymer matrix does not exist in these nanocomposites, the strong P(AA-BA) ionic interactions should also be involved in their mechanical

a)

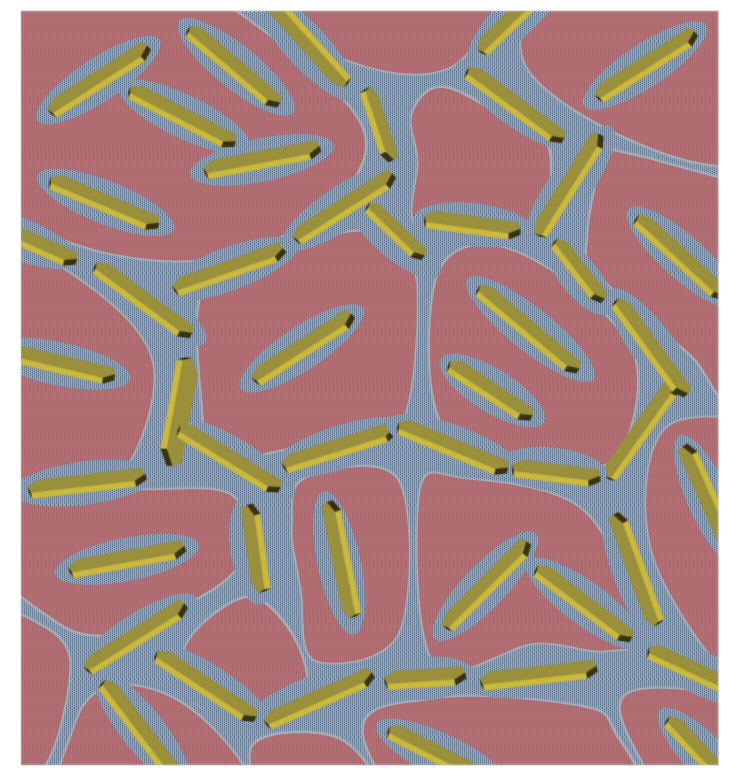

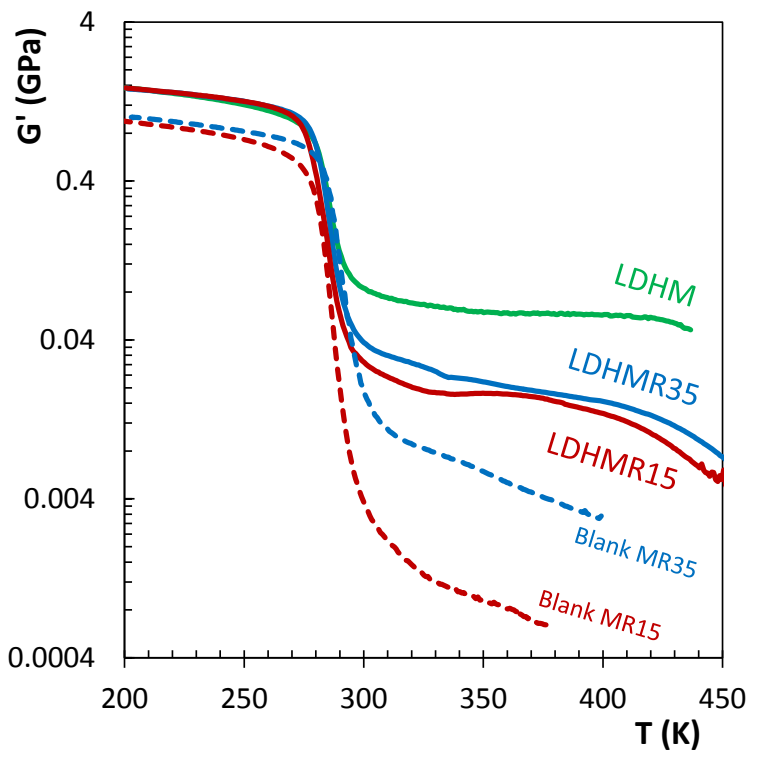

Figure 9 - Evolution of $\mathrm{G}^{\prime}$ and $\tan (\delta)$ as a function of temperature for the LDH-filled nanocomposites and the corresponding blank materials.

properties. Indeed, the large weight fraction of $\mathrm{P}(\mathrm{AA}-\mathrm{BA})$ blocks, and their much better affinity with the platelets than with the $\mathrm{P}(\mathrm{MA}-\mathrm{BA})$ blocks should promote the formation of a percolating $L D H / P(A A-B A)$ phase. Its existence would be consistent both with the modulus level of the nanocomposites in the rubbery plateau and the evolution of this modulus with temperature (as the ionic interactions are thermo-reversible). Within this assumption, the molar mass of the PA-BA block should not play a significant role in the mechanical properties of this phase, which would be also consistent with the very similar mechanical properties of LDHMR15 and LDHMR35 films. To sum up, Figure 10 depicts the morphologies of the three nanocomposites deduced from their microstructural and mechanical characterizations.

b)

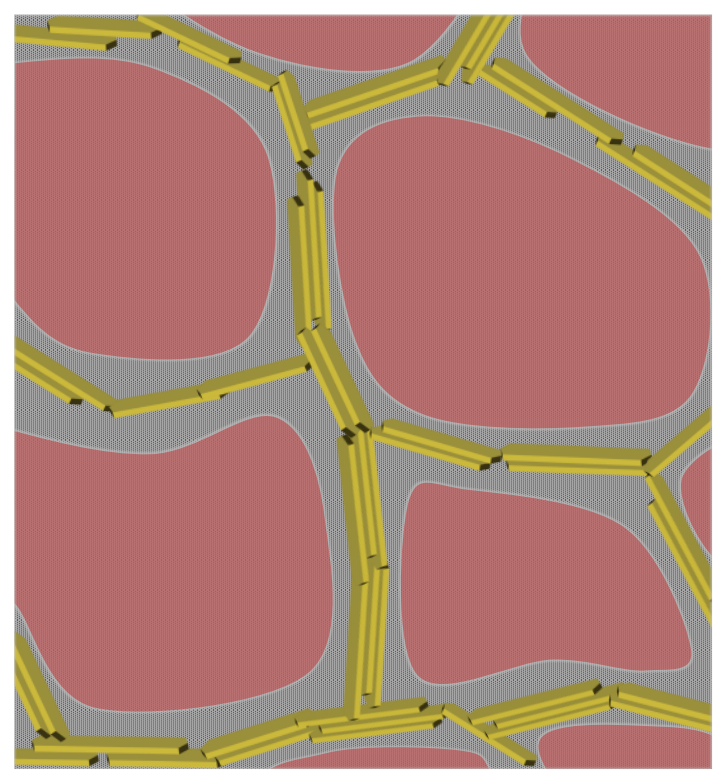

Figure 10 - Schematic representation of the assumed microstructure for a) LDHMR15 or LDHMR35 and b) LDHM nanocomposite films. P(MA-BA) is in light red, $\mathrm{P}(\mathrm{AA}-\mathrm{BA})$ shells are in blue mottled gray, and yellow platelets stand for LDH platelets. 


\section{Polymer Chemistry}

\section{ARTICLE}

\section{Conclusions}

LDH-filled nanocomposite films were processed from filmforming latexes synthesized by macroRAFT-assisted encapsulating emulsion polymerization (REEP), and compared with LDH-free analogues. From this synthesis route, the resulting polymer chains consisted in a assembly of, on one side, the macroRAFT agent (here AA-BA random copolymer) and, on the other side, the MA-BA random copolymer from the RAFT-mediated emulsion polymerization.

In a first step, such copolymers synthesized without LDH surprisingly showed a lamellar nanostructuration by SAXS and TEM. This can be ascribed to the strong ionic interactions within the $\mathrm{P}(\mathrm{AA}-\mathrm{BA})$ block, which promoted the phase separation and nanostructuration. Their thermomechanical behavior was significantly improved compared to a classical, non-ionic $\mathrm{P}(\mathrm{MA}-\mathrm{BA})$ latex film, displaying a high rubbery plateau and flowing of the material at higher temperature. The modulus level of the rubber-like plateau at high temperature strongly increased with the molar mass of the chains, i.e., with the number of chain entanglements between the $P(M A-B A)$ blocks and the number of physical crosslinks (through ionic interactions) within the $\mathrm{P}(\mathrm{AA}-\mathrm{BA})$ domains.

In a second step, LDH-filled latex nanocomposites were investigated. REEP gave rise to latexes that were made of encapsulated LDH platelets on which polymer chains were ionically anchored through the $\mathrm{P}(\mathrm{AA}-\mathrm{BA})$ block. The latex particles were most likely stabilized in water by a $P(A A-B A)$ shell. Once the water evaporated, nanocomposite films were obtained with a LDH content around $16 \mathrm{wt} \%$. Irrespective of the length of the macroRAFT used for the synthesis, a good dispersion of the LDH platelets within the polymer matrix and a strong mechanical reinforcement were observed for the nanocomposites. This behavior was mainly driven by LDH-LDH, $\mathrm{LDH}$-polymer chains and interchain ionic interactions, giving a microstructure consisting of a percolating $\mathrm{P}(\mathrm{AA}-\mathrm{BA})$-LDH phase and isolated $\mathrm{LDH}$ particles within a soft $\mathrm{P}(\mathrm{MA}-\mathrm{BA})$ matrix. As a comparison, a nanocomposite made of non-encapsulated LDH was synthesized. In this material, the $\mathrm{P}(\mathrm{AA}-\mathrm{BA})$ chains were not chemically bonded to the $\mathrm{P}(\mathrm{MA}-\mathrm{BA})$ ones and, as a result, all the LDH nanoplatelets were segregated at the latex beads surface with the $P(A A-B A)$. This gave rise to a highly percolating nanocomposite film which showed a higher rubber modulus plateau that was almost constant up to $430 \mathrm{~K}$.

By playing with the chemical structure of the polymer chains and the dispersion of the LDH nanoplatelets within the polymer phase by means of the latex synthesis by REEP, this study remarkably achieves a full tuning of thermomechanical properties for latex-based materials. A wide range of behavior has indeed been obtained: from a classical soft noncrosslinked $\mathrm{P}(\mathrm{MA}-\mathrm{BA})$ to a stiff percolating nanocomposite through intermediate ionic diblock copolymers.

\section{Conflicts of interest}

There are no conflicts to declare.

\section{Acknowledgements}

The authors are indebted to the "Microstructure Technological Center" (CT $\mu$ ) of University of Lyon for the access to the transmission electron microscope and the ultramicrotome. The authors acknowledge Damien Montarnal for fruitful discussions and financial support from ANR-11-JS08-0013.

\section{Notes and references}

1 E. Chabert, M. Bornert, E. Bourgeat-Lami, J. Y. Cavaillé, R. Dendievel, C. Gauthier, J. L. Putaux and A. Zaoui, Mater. Sci. Eng. A, 2004, 381, 320-330.

2 C. Chevigny, N. Jouault, F. Dalmas, F. Boué and J. Jestin, J. Polym. Sci. Part B Polym. Phys., 2011, 49, 781-791.

3 J. Faucheu, C. Gauthier, L. Chazeau, J.-Y. Cavaillé, V. Mellon, F. Pardal and E. B. Lami, Polymer, 2010, 51, 4462-4471.

4 J. Jancar, J. F. Douglas, F. W. Starr, S. K. Kumar, P. Cassagnau, A J. Lesser, S. S. Sternstein and M. J. Buehler, Polymer, 2010, 51, 3321-3343.

5 Y. Termonia, Polymer, 2010, 51, 4448-4451.

6 S. C. Tjong, Mater. Sci. Eng. R, 2006, 53, 73-197.

7 F. Dalmas, J.-Y. Cavaillé, C. Gauthier, L. Chazeau and R. Dendievel, Compos. Sci. Technol., 2007, 67, 829-839.

8 V. Favier, G. Canova, S. Shrivastava and J. Y. Cavaillé, Polym. Eng. Sci., 1997, 37, 1732-1739.

9 N. Jouault, P. Vallat, F. Dalmas, S. Saïd, J. Jestin and F. Boué, Macromolecules, 2009, 42, 2031-2040.

10 J. Oberdisse, A. El Harrak, G. Carrot, J. Jestin and F. Boué, Polymer, 2005, 46, 6695-6705.

11 Z. Zhu, T. Thompson, S.-Q. Wang, E. D. von Meerwall and A. Halasa, Macromolecules, 2005, 38, 8816-8824.

12 A. Noël, J. Faucheu, J.-M. Chenal, J.-P. Viricelle and E. BourgeatLami, Polymer, 2014, 55, 5140-5145.

13 Y. Cui, S. Kumar, B. Rao Kona and D. van Houcke, RSC Adv., 2015, 5, 63669-63690.

14 B. Tan and N. L. Thomas, J. Memb. Sci., 2016, 514, 595-612.

15 J. S. Meth, S. G. Zane, C. Chi, J. D. Londono, B. A. Wood, P. Cotts, M. Keating, W. Guise and S. Weigand, Macromolecules, 2011, 


\section{4, 8301-8313.}

16 S. S. Omara, M. H. Abdel Rehim, A. Ghoneim, S. Madkour, A. F. Thünemann, G. Turky and A. Schönhals, Macromolecules, 2015, 48, 6562-6573.

17 C. Chevigny, F. Dalmas, E. Di Cola, D. Gigmes, D. Bertin, F. Boué and J. Jestin, Macromolecules, 2010, 44, 122-133.

18 S. K. Kumar, N. Jouault, B. Benicewicz and T. Neely, Macromolecules, 2013, 46, 3199-3214.

19 M. Bailly, M. Kontopoulou and K. El Mabrouk, Polymer, 2010, 51, 5506-5515.

20 N. Suzuki, F. Yatsuyanagi, M. Ito and H. Kaidou, J. Appl. Polym. Sci., 2002, 86, 1622-1629.

21 L. Dewimille, B. Bresson and L. Bokobza, Polymer, 2005, 46, 4135-4143.

22 G. Jiang, S. Song, Y. Zhai, C. Feng and Y. Zhang, Compos. Sci. Technol., 2016, 123, 171-178.

23 R. K. Shah and D. R. Paul, Macromolecules, 2006, 39, 33273336.

24 E. Bourgeat-Lami, J. Faucheu and A. Noel, Polym. Chem., 2015, 6, 5323-5357.

25 E. Bourgeat-Lami and M. Lansalot, Adv. Polym. Sci., 2010, 33, 53-123.

26 E. Bourgeat-Lami, N. Sheibat-Othman and A. M. Dos Santos, in Polymer Nanocomposites by Emulsion and Suspension Polymerization, The Royal Society of Chemistry, 2011, pp. 269311.

27 J. Faucheu, C. Gauthier, L. Chazeau, J.-Y. Cavaillé, V. Mellon and E. B. Lami, Polymer, 2010, 51, 6-17.

28 A. Noël, J. Faucheu, M. Rieu, J.-P. Viricelle and E. Bourgeat-Lami, Compos. Sci. Technol., 2014, 95, 82-88.

29 P. Espiard, A. Guyot, J. Perez, G. Vigier and L. David, Polymer, 1995, 36, 4397-4403.

30 M. Pan, X. Shi, X. Li, H. Hu and L. Zhang, J. Appl. Polym. Sci., 2004, 94, 277-286.

31 E. Bourgeat-Lami, P. Espiard, A. Guyot, C. Gauthier, L. David and G. Vigier, Die Angew. Makromol. Chemie, 1996, 242, 105-122.

32 R. Ruggerone, C. J. G. Plummer, N. Negrete Herrera, E. Bourgeat-Lami and J.-A. E. Månson, Eng. Fract. Mech., 2009, 76, 2846-2855.

33 R. Ruggerone, C. J. G. Plummer, N. N. Herrera, E. Bourgeat-Lami and J. A. E. Månson, Eur. Polym. J., 2009, 45, 621-629.

34 R. Ruggerone, C. J. G. Plummer, N. N. Herrera, E. Bourgeat-Lami and J. A. E. Månson, Solid State Phenom., 2009, 151, 30-34.

35 N. Negrete-Herrera, J.-L. Putaux, L. David, F. De Haas and E. Bourgeat-Lami, Macromol. Rapid Commun., 2007, 28, 15671573.

36 E. Bourgeat-Lami, T. R. Guimarães, A. M. C. Pereira, G. M. Alves, J. C. Moreira, J.-L. Putaux and A. M. dos Santos, Macromol. Rapid Commun., 2010, 31, 1874-1880.

37 T. Wang, P. J. Colver, S. A. F. Bon and J. L. Keddie, Soft Matter, 2009, 5, 3842-3849.

38 D. G. Evans and R. C. T. Slade, in Layered Double Hydroxides, eds. X. Duan and D. G. Evans, Springer Berlin Heidelberg, Berlin, Heidelberg, 2006, pp. 1-87.

39 D. Basu, A. Das, K. W. Stöckelhuber, U. Wagenknecht and G. Heinrich, Prog. Polym. Sci., 2014, 39, 594-626.

40 Y. Gao, J. Wu, Q. Wang, C. A. Wilkie and D. O'Hare, J. Mater.
Chem. A, 2014, 2, 10996-11016.

41 L. Qiu and B. Qu, in Polymer Nanocomposites by Emulsion and Suspension Polymerization, The Royal Society of Chemistry, 2011, pp. 32-63.

42 C. Veschambres, M. Halma, E. Bourgeat-Lami, L. Chazeau, F. Dalmas and V. Prevot, Appl. Clay Sci., 2016, 130, 55-61.

43 D. Nguyen, H. S. Zondanos, J. M. Farrugia, A. K. Serelis, C. H. Such and B. S. Hawkett, Langmuir, 2008, 24, 2140-2150.

44 N. Zgheib, J.-L. Putaux, A. Thill, E. Bourgeat-Lami, F. D'Agosto and M. Lansalot, Polym. Chem., 2013, 4, 607-614.

45 A. C. Perreira, S. Pearson, D. Kostadinova, F. Leroux, F. D'Agosto, M. Lansalot, E. Bourgeat-Lami and V. Prevot, Polym. Chem., 2017, 8, 1233-1243.

46 M. Pavlovic, P. Rouster, E. Bourgeat-Lami, V. Prevot and I. Szilagyi, Soft Matter, 2017, 13, 842-851.

47 M. Pavlovic, M. Adok-Sipiczki, C. Nardin, S. Pearson, E. Bourgeat-Lami, V. Prevot and I. Szilagyi, Langmuir, 2015, 31, 12609-12617.

48 P. B. Zetterlund, S. C. Thickett, S. Perrier, E. Bourgeat-Lami and M. Lansalot, Chem. Rev., 2015, 115, 9745-9800.

49 M. Nagoshi, T. Kawano and K. Sato, Surf. Interface Anal., 2016, 48, 470-473.

50 L. Chazeau, C. Gauthier, G. Vigier and J. Y. Cavaille, in Handbook of Organic-Inorganic Hybrid Materials and Nanocomposites, Pt2, ed. H. S. Nalwa, American Scientific Publishers, 2004, pp. 63-111.

51 M. A. Van Es, Technische Universiteit Delft, 2001.

52 J. C. Halpin, J. Compos. Mater., 1969, 3, 732-734.

53 S. Mani, R. Weiss, C. E. Williams and S. F. Hahn, Macromolecules, 1999, 32, 3663-3670.

54 M. Chenal, J. Rieger, C. Véchambre, J.-M. Chenal, L. Chazeau, C. Creton and L. Bouteiller, Macromol. Rapid Commun., 2013, 34, 1524-1529.

55 M. Chenal, C. Véchambre, J.-M. Chenal, L. Chazeau, V. Humblot, L. Bouteiller, C. Creton and J. Rieger, Polymer, 2017, 109, 187196.

56 F. S. Bates and G. H. Fredrickson, Annu. Rev. Phys. Chem., 1990, 41, 525-557.

57 A. Eisenberg and J. S. Kim, Introduction to ionomers, WileyInterscience, 1998.

58 L. J. Fetters, D. J. Lohse, D. Richter, T. A. Witten and A. Zirkel, Macromolecules, 1994, 27, 4639-4647.

59 J.-S. Kim, K. Yoshikawa and A. Eisenberg, Macromolecules, 1994 27, 6347

60 M. Hara and A. Eisenberg, Macromolecules, 1987, 20, 2160.

61 L. F. Drummy, Y. C. Wang, R. Schoenmakers, K. May, M. Jackson, H. Koerner, B. L. Farmer, B. Mauryama and R. A. Vaia, Macromolecules, 2008, 41, 2135-2143.

62 V. Thakur, A. Das, R. N. Mahaling, S. Rooj, U. Gohs, U. Wagenknecht and G. Heinrich, Macromol. Mater. Eng., 2009, 294, 561-569. 